Resenhas

\title{
MÉTODOS DE PESQUISA A PARTIR DAS PERSPECTIVAS DE MICHEL FOUCAULT
}

Kleber Prado Filho ${ }^{1}$

${ }^{1}$ Professor aposentado do Departamento de Psicologia da Universidade Federal de Santa Catarina (UFSC). Florianópolis Santa Catarina. E-mail: kleberprado.psi@gmail.com

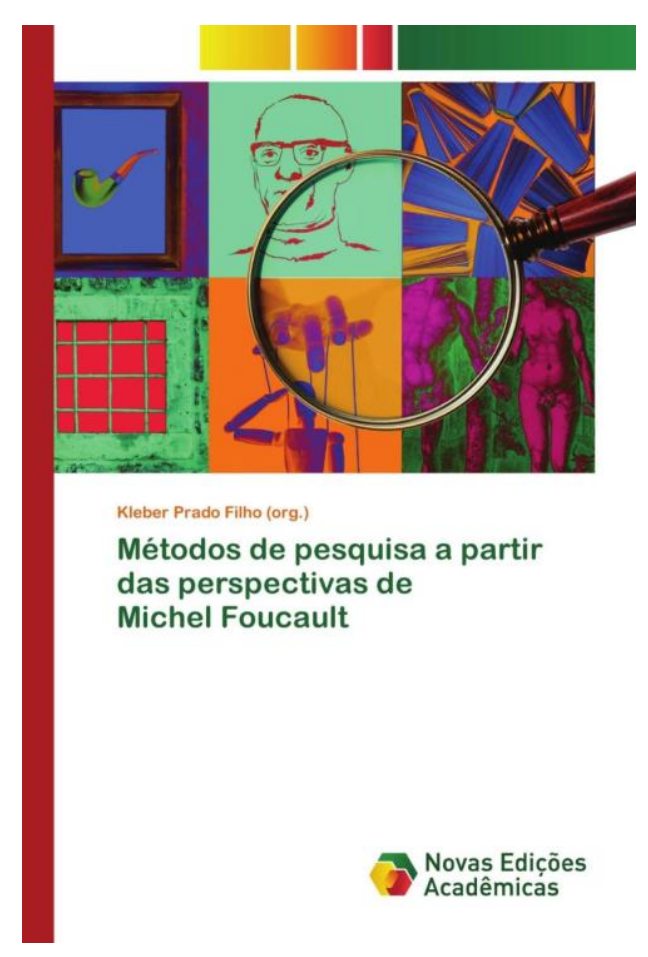

Submetido em 25/06/2021 Aprovado em 29/06/2021

Esta resenha apresenta a curiosa característica de não ser a apreciação de um leitor, mas a posição do autor a respeito do seu próprio texto, o que dificulta certo distanciamento necessário a uma leitura crítica. Assim, procurarei ressaltar aqui aspectos que considero relevantes tanto no que diz respeito aos motivos concretos e à própria motivação pessoal envolvidos no projeto e produção do material, quanto em relação ao conteúdo mesmo que ali se apresenta.

Antes de mais nada, este trabalho resulta de longa vivência acadêmica, de demandas, desafios e interpelações em termos teóricos e práticos relativos ao desenvolvimento de pesquisas a partir das perspectivas histórico-críticas de Michel Foucault. 


\section{Saberes Plurais: Educação na Saúde}

Este autor dispensa apresentações, porém, apenas para situar a leitura que dele faço - que é bastante engajada e comprometida - devo dizer que o considero um dos maiores filósofos do século $\mathrm{XX}$, que atravessa para o século XXI, cujo pensamento permanece vivo, vibrante, oferecendo ainda respostas, tanto em termos teóricos quanto práticos, para questões que nos inquietam hoje, o que faz dele um pensador contemporâneo - para além da sua morte em 1984 - e cujas aplicações metodológicas são instrumentos de pesquisa e de luta social, tendo em conta que operam de perspectivas histórico-críticas. Exemplo disso? ....a problematização do panóptico e da vigilância na modernidade, que resulta na multiplicação da vigilância eletrônica contemporânea em espaços fechados mas também abertos; a questão das biopolíticas modernas, governo político centrado na vida e saúde das populações e governo médico do sujeito sobre si mesmo, seu corpo, sua saúde, nossa contemporânea medicalização da vida e seus desdobramentos na pandemia que estamos vivendo: o isolamento social, o uso da máscara, o cuidado consigo e com os outros.

Voltando ao livro objeto desta resenha, deve-se apontar que o conteúdo ali exposto resulta de estudos e aulas sobre métodos de pesquisa a partir das perspectivas do autor, debates metodológicos entre orientador e orientandos, orientandos entre si, atividades do Grupo de Pesquisa Michel Foucault ao longo de alguns anos - tal como indicado na 'Introdução' do trabalho podendo ser considerado uma produção coletiva, materialização de um projeto metodológico que avance em termos de aprofundamentos teórico-práticos relativos às suas problematizações.

Trata-se, neste sentido, de uma contribuição importante para estudos centrados nas análises do autor, que além de aprofundar o olhar, reúne uma grande diversidade de elementos díspares e complexos dispersos em sua extensa produção intelectual, seus chamados 'ditos e escritos': aulas, palestras, cursos, artigos, introduções de livros e estudos, o que vem a preencher uma lacuna. Devese notar que a questão metodológica é central em suas análises, ao mesmo tempo que é bastante complexa e intricada, havendo uma grande demanda por estudos que reúnam esta disparidade e consigam transitar por sua complexidade e suas interconexões.

Tendo em conta essas breves considerações passo a um detalhamento do material ali exposto, destacando que este reúne e apresenta de forma interligada e articulada as estratégias referentes às propostas metodológicas de Michel Foucault.

Logo de saída encontra-se ali uma introdução bastante consiste em termos teórico-práticos, que faz um voo panorâmico sobre as análises do autor - não por isso, raso - que propõe uma leitura articulada dos seus estudos, ao mesmo tempo que mostra suas diferenças e sua diversidade, seus desníveis e sutilezas. É muito difícil produzir um texto, até certo ponto didático, sobre Foucault sem incorrer em uniformizações, padronizações e/ou simplificações e o que este texto introdutório 


\section{Saberes Plurais: Educação na Saúde}

pretende é apresentar as suas estratégias metodológicas em suas conexões com questões teóricas, em sua complexidade, diversidade, diferenças, dispersão e, principalmente, movimento, sem produzir nivelamentos.

Na sequência do volume vem o primeiro texto metodológico sobre 'Arqueologia do Saber' como estratégia de análise do discurso, de muito interesse para filósofos, estudiosos da linguagem, linguistas, escritores, críticos literários, psicanalistas - particularmente lacanianos -, toda uma diversidade de estudiosos, hermeneutas e interessados no central e complexo problema do discurso. O campo da análise do discurso é amplo, multifacetado, problematizado a partir de múltiplas e diversas perspectivas e Michel Foucault entra nesse domínio, nesse debate, de forma históricocrítica, questionando o lugar ali ocupado pelo sujeito; as relações sujeito x objeto; o próprio objeto em sua substância; as relações subjetividade $\mathrm{x}$ verdade, desnaturalizando a subjetividade $\mathrm{e}$ colocando sob suspeita os jogos de produção de verdade do discurso moderno, expondo seu caráter político. A grosso modo, tomadas em seus movimentos, são estas as trajetórias percorridas neste tratamento do discurso a partir da perspectiva de Foucault.

O segundo texto metodológico refere-se à 'Genealogia do Poder' como estratégia de análise de práticas e relações de poder - a rigor poderes, no plural. O que está em questão ali é uma perspectiva micropolítica de poder - micropoderes - microfísica do poder: as disciplinas, práticas de produção de corpos e subjetividades, práticas de individualização, de normalização, práticas de vigilância, práticas de objetivação e subjetivação de sujeitos, relações saber x poder x subjetividade, práticas de resistência. A leitura ali realizada mostra também a problematização do surgimento histórico dos biopoderes na modernidade: o governo sobre a vida dos indivíduos e da população, questão bastante atual, objeto de uma multiplicidade de pesquisas e estudos acadêmicos, apontando possibilidades de aplicações metodológicas críticas a partir do olhar de Michel Foucault.

O texto metodológico apresentado na sequência trata da 'Genealogia da Ética' como estratégia de análise de relações do sujeito consigo mesmo, problematizando práticas e trabalhos do sujeito sobre si mesmo, produções de si mesmo, estetizações de si, dos corpos, da subjetividade, a moderna e narcísica tecnologia de si mesmo em conexões com a questão da saúde, dietéticas, cuidados consigo mesmo, com o corpo, modos e práticas de subjetivação, práticas liberdade. Estas são também questões bastante contemporâneas que se colocam como objetos de pesquisas diversas em desenvolvimento nas áreas de ciências humanas e sociais, da educação, entre outras, que podem ser tratadas de forma crítica e política a partir da perspectiva foucaultiana, conforme aponta a leitura ali exposta. 


\section{Saberes Plurais: Educação na Saúde}

$\mathrm{O}$ próximo texto refere-se à 'Cartografia' como estratégia de enfrentamento e desmontagem de dispositivos de poder, questão central à política moderna e, por isso mesmo, aos pensamentos de Foucault e Deleuze, mostrando ser este um método elaborado a quatro mãos pelos dois autores. Cartografia não como 'ciência dos mapas', mas como cartografia social, que traça diagramas de forças, de movimentos e linhas de poder, articulações e fluxos políticos, agenciamentos de forças, modos de subjetivação, práticas de resistência e liberdade. Os dispositivos são conjuntos díspares de articulações políticas - microfísicas - que se formam em torno de questões centrais e estratégicas que se colocam como problemas a serem enfrentados por nossas sociedades tanto em termos teóricos quanto práticos, tais como: educação, produção, loucura, sexualidade, entre outras. Mais uma vez, a leitura ali apresentada aponta possibilidades e estratégias metodológicas para estudos e pesquisas relativos a temáticas tão atuais quanto importantes, interessantes e desafiantes.

O último texto apresentado no livro - não menos importante que os outros - mostra a aplicação metodológica de algumas estratégias anteriormente tratadas, realizada por uma orientanda deste autor numa pesquisa de dissertação de mestrado, que objetiva traçar trajetórias históricas de uma 'Genealogia das práticas de saúde pública no Brasil' a partir do período imperial. Colocando em movimento de maneira bem prática alguns conceitos explorados, o estudo documental lança um olhar descontínuo sobre fluxos e linhas de força, jogos de enunciação e verdade, apontando proveniências, emergências de objetos, acontecimentos, enfrentamento de posições, jogos e articulações de poder, além de rupturas históricas - questões genealógicas fundamentais - ao longo dos séculos XIX e XX, dando visibilidade, em diferentes momentos da história sanitária brasileira, à predominância dos enunciados do higienismo, sanitarismo, preventivismo e promoção de saúde, este último, emergente no final do século passado.

Esta resenha, por ter sido escrita pelo autor do livro, acabou assumindo um tom de apresentação, no entanto, creio haver cumprido seu papel de orientar o leitor na exploração do material, que também acredito, ser da maior utilidade para pesquisadores a partir da perspectiva de Foucault, mas não apenas estes, também todos aqueles que busquem uma orientação e aplicação histórico- político-crítica aos seus estudos. Muito obrigado e boa leitura!

\section{Referências}

PRADO FILHO, K. (org.). Métodos de pesquisa a partir das perspectivas de Michel Foucault. Beau Bassin: Novas Edições Acadêmicas, 2021. 